which is similarly twisted by the rotation of that sphere and provides a much larger field with lines of force around the axis of rotation. This induced field in its turn is propagated back to the first sphere, where it provides the primary field which is twisted by the rotation of the latter. With roughly half the possible directions of the axes of rotation, the dynamo interaction amplifies the existing field. Herzenberg finds it necessary to discuss the reflexion of magnetic fields at the boundary of the large sphere, but it is difficult to believe that this can have any decisive importance to maintenance of the dynamo.

Herzenberg's mechanism possesses definite advantages from the mathematical point of view. If the distance between the centres of the smaller spheres is sufficiently great, the higher-order harmonics of the field which is induced by the rotation of one sphere are strongly attenuated before they reach the other sphere. This ensures the convergence of the expansions used by Herzenberg; a large part of his paper is, in fact, concerned with the convergence. The mechanism also has the advantage that the method of feedback is clearly evident; in Bullard and Gellman's work the same mass of fluid partook of two different sorts of motion at the same time, and it was virtually impossible to separate the effects of the two motions.

Like other earlier workers, Herzenberg made no attempt to consider the reaction of the induction process on the motion which causes it, and indeed his mechanism does not lend itself to considering such a reaction. The reaction must clearly be important, and be responsible for the tendeney for the Earth's magnetic axis to approximate to its axis of rotation. Thus the importance of Herzenberg's work is primarily not physical, but mathematical. It decisively clears up any lurking doubts about the dynamo theory due to defects of convergence in earlier discussions. In considering the physical picture it is now no longer necessary to worry lest deeper research may show that failures of convergence invalidate the whole dynamo hypothesis.

T. G. Cowling

\title{
RAILWAY ECONOMICS
}

\begin{abstract}
A LTHOUGH it appeared after the House of A Commons debate on December 11, when the Transport (Borrowing Powers) Bill received its second reading, the broadsheet, "Paying for the Railways" (No. 429. December 19, 1958), issued by Politica] and Economic Planning, throws much further light on the problem of the future of railways, reviewing briefly the origin of the financial difficulties of British Railways since the War, the policies recently proposed, including the problem of wages, and finally setting forth four possible alternative solutions. In. moving the second reading of the Bill, Clause 1 of which extends the borrowing powers of the British Transport Commission by a further $£ 600$ million, the Minister of Transport and Civil Aviation, Mr. H. Watkinson, said that the crux of the problem was how the railway system of the Victorian age could streamline itself to fit the age of the motor-car and nuclear power. For the first forty-four weeks of 1958 merchandise traffic was 14 per cent below 1957 and 10 per cent on 1956 . Nevertheless, the Commission was pressing on with modernization of heavy traffic, but it was inevitably slow and took long to come to fruition. By the end of 1958, fitted freight trains would represent 35 per cent of the whole and wagons fitted with continuous brakes number 270,$000 ; 44,000$ containers suitable for door-to-door carriage would be in use, 150 older marshalling yards would be closed and 27 new yards constructed. Each working day 4 million passengers and 1 million tons of freight were moved.

Mr. Watkinson said a severe fall in heavy freight traffic in the last two months of the year was the main cause of the deficit for the year, which is expected to be about $£ 85$ million. Transport of coal was at present down by about 500,000 tons a week; production of crude steel in 1958 was probably about 10 per cent lower than in 1957, and the Commission's report indicates a fall in receipts from coal and mineral transport of more than $£ 600,000$ a week on 1957, but assumes that this is a temporary decline, calling for temporary measures only.
\end{abstract}

Mr. Watkinson said that at his request the Commission had already initiated a full, detailed and urgent review of the whole modernization plan, taking account of both present and probable changes in traffic in the light of the probable level of activity in the coal industry, in view of competition from oil and future developments in nuclear energy. $\mathrm{He}$ hoped to lay the findings of this review before Parliament by the early spring. Meanwhile, with the Government's full support, the Commission was proceeding with more modernization on a narrower front. It proposed to concentrate resources for main-line electrification on the London Midland and Scottish line to Manchester and Liverpool and to accelerate its completion by several years. The introduction of diesel locomotives to eliminate the use of steam would be accelerated as quickly as possible on an area basis, particularly on routes north of Newcastle upon Tyne: by 1961 nearly 1,100 main line diesel locomotives would be in use. Multi-unit diesel trains would be doubled, from 2,300 to 4,600 , by the end of 1961 . As a result of these and other measures the Commission expected to achieve additional savings of at least $£ 30$ million in a full year. Although there had been a reduction in the labour force of 20,000 during the past year, this had been effected with proper agreements between the Commission and the trade unions. In replying on the debate, Mr. C. R. H. Nugent, Joint Parliamentary Secretary to the Ministry, referred to the encouraging position of passenger services, revenue for which in November 1958 showed an increase of $£ 0.3$ million on 1957. The Minister himself also referred to the success of some of the luxury trains and to the Commission's intention to pursue a more flexible policy in fares.

Dealing with the modernization programme, first published in 1955, the Planning broadsheet agrees that the most important feature, the gradual substitution of electric or diesel traction for steam locomotives, as well as the plans for extending automatic train control and colour light signalling, fitting 
all goods trains with vacuum brakes, the improvement of express train services and provision of doorto-door containers, should both provide economies and improve the quality of passenger and freight services. If the expectations of the Commission are justified, the initial cost of the modernization programme should be covered by improved revenues, and there is no justification for slowing down the programme to remove an immediate financial predicament.

The broadsheet is more critical of the policy of cutting uneconomic services, and while some adaptation of railway services is obviously necessary in the light of those provided by road hauliers and road passenger undertakings, Political and Economic Planning does not consider it is always in the interest of the railways to cut their services to solve an immediate financial problem. In reducing the frequency of passenger services the railways are following a dangerous policy of reducing costs by lowering the standard of their service, and experiment with the variety of alternative means of cur. tailing losses is advocated. Rejecting as economically unsound a flat subsidy without any re-organization of the national transport system, it points out that the solution of allowing the railways to operate purely as a commercial undertaking would involve a break with their long tradition of public service obligations. Although this would probably not cause serious hardship because so many alternative forms of private transport are now available, it is politically controversial although economically sound.

That also applies to the solution by joint control of the transport system as a whole by the same undertaking, as was envisaged when the British Transport Commission was created. The merits of the transport structure which emerged from nationalizing road haulage and long-distance ' $C$ ' licence road transport, however, would depend on the way in which co-ordination plans were formulated and implemented. The solution suggested by J. R. Sargent as a solution to the problem of unremunera. tive public transport services depends on a compromise between a commercial undertaking and a public service with the merits of each clearly defined, and has the merit of being politically neutral on the question how far the railways should function as a public service, since the decision how many, and which, services should be subsidized is referred to another authority. It could be applied without imposing any drastic changes on the ownership of the rest of the transport sector. The choice between any of these solutions, however, involves first a Government decision whether it wishes unremunerative services to be continued. If so, the Government must decide how these services should be financed, and in choosing the method to be used, the effects on the efficiency of transport as a whole and on the current distribution of work between road and rail require careful examination. Finally, Political and Economic Planning insists that decisions on these matters are urgent.

\title{
POSSIBLE ENZYMIC MECHANISM FOR THE DEVELOPMENT OF RESISTANCE AGAINST FLUOROURACIL IN ASCITES TUMOURS
}

\author{
By Dr. PETER REICHARD and OLA SKÖLD \\ Department of Chemistry I, Karolinska Institutet, Stockholm, Sweden \\ AND \\ Prof. GEORGE KLEIN \\ Department of Tumour Biology, Karolinska In stitutet, Stockholm, Sweden
}

\begin{abstract}
$\mathrm{T}$ HE uracil analogue 5-fluorouracil was introduced by Heidelberger et al. ${ }^{1}$ as an antimetaboliteinhibiting tumour growth. In extensive metabolic studies ${ }^{2-5}$ it was demonstrated that the pyrimidine was incorporated into ribonucleic acid of both normal tissues and tumours and, furthermore, that the compound inhibited the incorporation of labelled formate and uracil into deoxyribonucleic acid-thymine of Ehrlich ascites cells both in vivo and in vitro. The latter finding together with similar results by Eidinoff et al. ${ }^{6}$ suggested a block in the methylation of deoxyuridine$5^{\prime}$-phosphate. Cohen et al. ${ }^{7}$ recently demonstrated such an inhibition of thymidine-5'-phosphate synthetase from $E$.coli by 5 -fluorodeoxyuridine- $5^{\prime}-$ phosphate.

These studies indicate two points at which the fluoropyrimidine might interfere with nucleic acid metabolism ${ }^{1,5}:$ (1) inhibition of synthesis of deoxyribonucleic acid through the inability of the cells to synthesize thymine ; (2) formation of a 'fraudulent' ribonueleic acid containing fluorouracil in place of
\end{abstract}

uracil. Both mechanisms seem to require a transformation of the fluoropyrimidine to the nucleotide stage, and such transformations to fluorouridine phosphates and fluorodeoxyuridine- $5^{\prime}$-phosphate, respectively, were also observed to occur in the ascitic cells $\mathrm{s}^{3,5}$. In line with this idea is also the demonstration that in several tumours 5-fluorouridine and/or 5 -fluorodeoxyuridine had a considerably higher tumour-inhibiting activity than the free pyrimidine ${ }^{8}$.

Fluorouracil also strongly inhibits uridine phosphorylase ${ }^{9}$ and thus inhibits synthesis of ribonucleic acid from uracil. This type of inhibition might also contribute to the carcinostatic activity of the compound.

One of our laboratories has for some time been interested in the utilization of uracil for synthesis of nucleic acid as an alternative mechanism for pyrimidine synthesis ${ }^{10}$. It was found that the Ehrlich ascites tumour possessed relatively high activities of the enzymes uridine phosphorylase and uridine 